Original

Article

\section{Role of external irradiation in high-risk resected colon cancer}

\author{
Ahmadloo Niloofar, Mosalaei Ahmad, Omidvari Shapour, Mohammadianpanah \\ Mohammad \\ Department of Radiation Oncology, Nemazee Hospital, Shiraz University of Medical Sciences, Shiraz, \\ Iran
}

Correspondence to: Mohammadianpanah Mohammad, E-mail: mohpanah@sums.ac.ir

\begin{abstract}
BACKGROUND / AIM: The best therapeutic modality for colon cancer "one of the most common malignancies of human being" is surgical resection of primary tumor. Adjuvant chemotherapy can help surgery to have a higher control and survival rate in high-risk resected patients, but the role of radiation therapy is the place of debate. This study was carried out to evaluate the possible role of adjuvant radiotherapy in such cases. MATERIALS AND METHODS: This retrospective trial evaluated 65 eligible patients with surgically resected high-risk colon carcinoma (serosal and/or lymph node involvement), from May 1986 to February 2000. The patients were categorized into two groups. The first group was treated with chemotherapy alone and the other with chemo-radiotherapy. Chemotherapy included 5.FU $500 \mathrm{mg} / \mathrm{m}^{2} / 5$ days for 6-8 courses and radiotherapy consisted 45-55 Gy with 1.5-2 Gy/fraction. Minimum follow-up was 36 months. RESULTS: Mean event-free survival was 140 and 101 months in chemotherapy and combined-therapy groups, respectively $(P=0.099)$. Local recurrence rate was detected as $9.7 \%$ in the chemotherapy arm and $23.5 \%$ in the combined-therapy arm $(P>0.1)$. Treatment-related morbidity and mortality has been significantly higher in the radiation arm $(P<0.001)$. CONCLUSION: Postoperative external radiation as adjuvant treatment does not improve local control of the patients with colon carcinoma.
\end{abstract}

Key words: Colon cancer, Radiation therapy, Surgical resection, Chemotherapy, Adjuvant treatment

\section{Introduction}

Colorectal carcinoma is the third common cancer and the fourth leading cause of cancer death worldwide. ${ }^{[1-2]}$ It affects both sexes approximately equally. ${ }^{[3]}$

Potentially curative treatment for colorectal carcinoma is surgical resection. ${ }^{[4]}$ The risk of locoregional failures following resection depends on the extent of disease. Patients with locally advanced resected tumor (nodal and/or serosal involvement) have higher risk of failures. Locoregional recurrence occurs in $20-50 \%$ and distant metastases in $20-30 \%$ of cases with surgery alone. ${ }^{[5-6]}$ The most common sites of involvement are liver, lung and peritoneum. ${ }^{[7-8]}$

Adjuvant chemotherapy improves survival in high-risk colorectal carcinoma (Stage B2-C3) by decreasing distant and local failure. ${ }^{[9-11]}$

Postoperative radiation therapy improves local control in high-risk resected rectal cancer, but its role in cancer of colon proper is not well defined. ${ }^{[12-14]}$

In the current retrospective analysis we studied the possible effect of adjuvant radiotherapy in high-risk resected colon cancer.

\section{Material and Methods}

This retrospective study included 83 cases with resectable high-risk colon carcinoma (Stage B2-C3) that were referred to the Radiotherapy department of the Nemazee hospital of Shiraz, Iran from May 1986 to 
February 2000. They were treated with chemotherapy with or without radiotherapy based on their physician's preference. Between 1986 to 1995 most of patients received chemoradiation and then because of irradiation toxicity and change of policy, most physicians preferred chemotherapy alone. The records of patients were got as the source of data that were analyzed retrospectively. They were staged according to the modified Astler coller system and UICC TNM.

The patients were categorized into two groups. Thirtyone patients in the first arm as chemotherapy group were being treated with adjuvant 5 . FU based chemotherapy alone and 34 cases received chemotherapy (5.FU based) plus postoperative radiotherapy, as the second arm. Eighteen cases were not eligible for analysis because of incomplete treatment course or loss of follow-up.

There were 14 females and 17 males in the chemotherapy group with mean age of $50 \pm 13$ years ranging from 32 to 77 years.

In the combined-therapy group, 22 patients were male and 12 cases were female. The mean age was $46 \pm 12$ years, with a range from 20 to 65 years. Table 1 shows Patients' characteristics. Surgical procedure included partial or hemicolectomy and pericolic lymph node dissection. Because of the belief that intraperitoneal failure is a common event in colon carcinoma, whole abdominopelvic irradiation was a component of radiotherapy in earlier days, but after that due to radiation toxicity, the attendant physician changed the field to a localized port.

Radiation portals were localized in 16 patients and were designed to encompass the tumor bed and nodal area with a 4 to $5 \mathrm{~cm}$ margin around it, 15 cases received whole abdominopelvic irradiation for $20 \mathrm{~Gy}$ and then continued with localized field. Using Co-60 machine, anterior-posterior and posterior-anterior fields, all portals were being treated every day with a 1.5-2Gy conventional daily fractionation delivering a total dose of 45-55Gy. Kidneys were shielded posteriorly after 15 Gy. The liver and kidney did not receive more than 20 and 18 Gy respectively. The small bowel got at the most 20 Gy with a probable higher dose to some localized part.

The tumor bed was defined by combining information from the preoperative barium enema and CT scan, pathologic findings and when available by surgical clips placed to outline the tumor bed. Irradiation was started at the second course of chemotherapy.

Chemotherapy included $5 . \mathrm{FU} 500 \mathrm{mg} / \mathrm{m}^{2}$ and leucovorin $20 \mathrm{mg} / \mathrm{m}^{2}$ using five consecutive days monthly for 6-8 courses.

Table 1: Clinical and pathological characteristics of patients

\begin{tabular}{|c|c|c|c|c|c|c|c|}
\hline \multirow[t]{2}{*}{ Characteristics } & & & \multicolumn{2}{|c|}{ Group 1} & \multicolumn{2}{|c|}{ Group 2} & \multirow[t]{2}{*}{ P ValueChi square } \\
\hline & & & Number & Percent & Number & Percent & \\
\hline \multicolumn{8}{|l|}{ Sex } \\
\hline Male & & & 17 & 54.8 & 22 & 64.7 & 0.417 \\
\hline Female & & & 14 & 45.2 & 12 & 35.3 & \\
\hline \multicolumn{8}{|l|}{ Tumor location } \\
\hline Cecum & & & 4 & 12.9 & 8 & 23.5 & \\
\hline Ascending colon & & & 7 & 22.6 & 7 & 20.6 & 0.733 \\
\hline Transverse colon & & & 4 & 12.9 & 4 & 11.8 & \\
\hline Descending colon & & & 6 & 19.4 & 8 & 23.5 & \\
\hline Sigmoid & & & 10 & 32.2 & 7 & 20.6 & \\
\hline \multicolumn{8}{|l|}{ Tumor grade } \\
\hline Well differentiated & & & 19 & 61.3 & 18 & 52.9 & \\
\hline Moderately differentiated & & & 8 & 25.8 & 9 & 26.5 & 0.971 \\
\hline Poorly differentiated & & & 4 & 12.9 & 7 & 20.6 & \\
\hline Modified Astler-coller staging & UICC TNM & & & & & & \\
\hline B2 & T3 NO MO & $\| \mathrm{A}$ & 16 & 51.6 & 16 & 47.1 & \\
\hline B3 & T4 NO MO & IIB & 4 & 12.9 & 4 & 11.8 & \\
\hline $\mathrm{C} 1$ & T1-2 N1-2 M0 & IIIA & 1 & 3.2 & 0 & 0 & 0.681 \\
\hline $\mathrm{C} 2$ & T3-4 N1-2 M0 & IIIB-C & 5 & 16.1 & 8 & 23.5 & \\
\hline C3 & T3-4 N1-2 M0 & IIIB-C & 5 & 16.1 & 6 & 17.6 & \\
\hline
\end{tabular}


Local failure was defined as recurrence occurring within the tumor bed, adjacent organs by direct extension or in regional nodal groups and distant metastases as failure in other sites other than mentioned above. Event-free survival was considered as time of surgery until recurrence (local or distant).

Patients were followed at regular intervals every 3 months for 2 years, every 6 months for another 3 years and then annually.

In each visit, history and physical examination, stool guaiac study, liver function tests (LFT), complete blood count (CBC), and carcinoembryonic antigen (CEA) was performed.

Colonoscopy, abdominal sonography or CT scan and CXR were taken annually. Minimum follow-up was 36 months.

We analyzed retrospectively using Kaplan-Meier survival curves (SPSS version 11.5) for survival distributions and log-rank test for the difference between the survival distributions. It would be more reliable if the patients were divided into subgroups according to site of cancers and specific characteristics like perforation and abscess but small numbers in each group would have made such a classification restricted and unreliable. To compare the differences of age, sex, grade, stage and site of disease between two groups, chi-square test has been used.

\section{Results}

Mean event-free survival time was 140 months (95\% $\mathrm{CI}=114-174)$ in the chemotherapy group and 101 months $(95 \% \mathrm{CI}=76-127)$ in the combined-therapy group $(\mathrm{P}=0.151)$.

Six out of $31(19.4 \%)$ patients had a relapse in the chemotherapy group. The time to failure ranged from 9 to 39 months with a median of 10 months. Of these six patients with relapse, three had local recurrence and three patients developed distant failure.

In the combined-therapy group 13 out of $34(38.2 \%)$ patients had relapse. Median time to failure was 8 months ranging from five to 120 months. Eight patients had local recurrence and five cases had distant metastases. Liver metastases was the most common site of distant failure in both groups.

The local recurrence rate was $9.7 \%$ and $23.5 \%(\mathrm{P}=$ 0.137 ) and 3 -year disease-free survival was $86.6 \%$ and $65.8 \%$ in the chemotherapy group and combined-

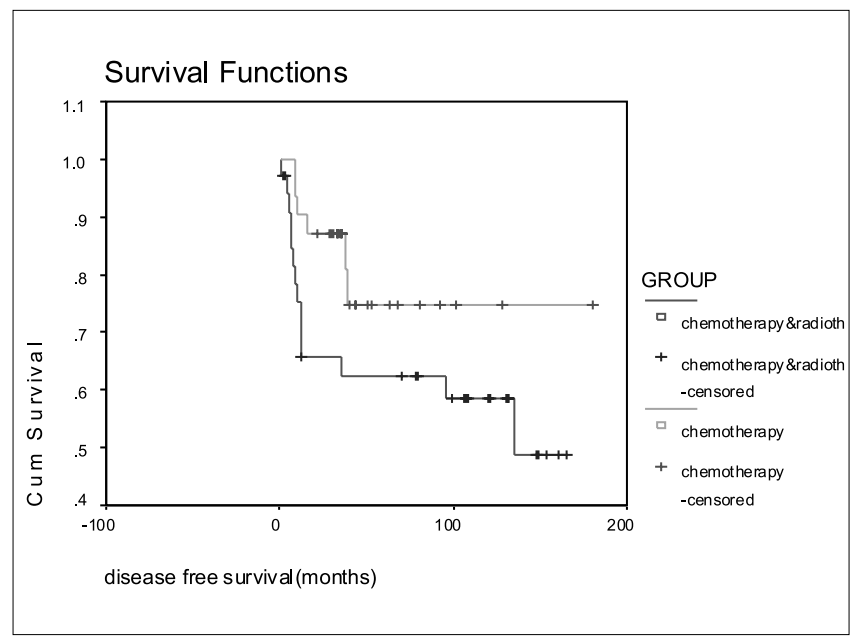

Figure 1: Disease - free survival of the patients

therapy respectively. [Figure 1] shows Survival curves. Using log-rank test indicates none of the differences between two arms reaches statistical significance.

Treatment tolerance in the chemotherapy group was excellent and only one bowel obstruction was observed and that was removed surgically. In the combinedtherapy group there were four bowel obstruction patients and 11 patients experienced severe early GI complications (nausea, vomiting and diarrhea) and one patient had GU side effects (dysuria and urinary infection) and nine cases had mild complaints $(\mathrm{P}<$ $0.001)$. There was no statistically significant difference for age-sex-grade-stage and site of disease between these groups according to the Chi-square test.

\section{Discussion}

Patterns of failure in colon cancer have been analyzed in various series. Data from these series show that local recurrence is a significant problem, especially in highrisk patients. In one retrospective study the local recurrence in these patients was 30\%-49\%. ${ }^{[5]}$ Therefore, a modality which is able to decrease this high rate of failure, has been sought in different studies mainly by means of radiation therapy. However, the difference of natural history with rectal cancer for which external radiation is an established adjuvant modality has been the cause of controversy and different outcomes in various series. The effect of external radiation in the local control of colon carcinoma is not clear. There are some published data on the use of adjuvant irradiation for this cancer. Kopelson retrospectively analyzed 22 patients irradiated postoperatively in an adjuvant fashion to regional fields, and compared them with a larger group of non-irradiated patients. He concluded that local control was improved when adjuvant irradiation 
was used. ${ }^{[15-16]}$ In a series with Sheild, 103 patients with high-risk resected colon cancer stage $\left(\mathrm{B}_{2-} \mathrm{C}_{3}\right)$ were treated with adjuvant postoperative radiotherapy to the tumor bed and found improved local control and survival compared to historical controls. ${ }^{[17]}$ Willett gave adjuvant external irradiation to 203 patients with locally advanced resected colonic cancer and significant improvement in local control and disease-free survival for patients with stages $\mathrm{T}_{4} \mathrm{~N}_{0} \mathrm{M}_{0}$ or $\mathrm{T}_{4} \mathrm{~N}_{1-2} \mathrm{M}_{0}$ disease compared to historical controls was observed. ${ }^{[18]}$ Estes also found a reduction in local failure using adjuvant irradiation. ${ }^{[19]}$

In a randomized trial Martenson studied 222 patients with high-risk resected ascending or descending colon carcinoma (T3-4 N1-2 M0) but due to poor accrual, 187 patients were eligible. They were randomly assigned to receive 12 cycles of bolus 5 . FU plus levamisole in one group with radiation and in the other group without irradiation. In the chemoradiotherapy group, radiation was 45-50. 4 Gy delivering 4 weeks after starting chemotherapy. Event-free survival was equal $(51 \%)$ in both groups and the overall survival was $62 \%$ and $58 \%$ for the chemotherapy and chemoradiation arms respectively $(\mathrm{P}>0.5)$. Hematologic toxicity was significantly higher in the chemoradiation arm $(\mathrm{P}=0.02)$ but non-hematologic complications were the same in both groups. They concluded that there is no statistically significant difference in the overall or disease-free survival between the chemotherapy and chemoradiation arms. ${ }^{[20]}$

In this study event-free survival was not significantly different between those who got radiation and those who did not $(65.8 \%$ versus $86.6 \%$ respectively), of course with a longer follow-up in the combined-therapy group that may be partly the cause of not statistically significant higher recurrence rate in this group. However, treatment-related side effects, especially late complications were higher in those who received radiation too $(3.2$ versus 11.8$)$. This higher rate of morbidity may be due to the use of not-up-to-date techniques and X-rays energy and overcome using higher energy, multiple and smaller fields or 3D technique, if available. With such techniques we might have reduced toxicity although its value remains to be proved.

Nonetheless, the result obtained from the current study is not in favor of increasing local control with postoperative external radiotherapy in high-risk resected colon cancer. Anyhow, the results should be interpreted cautiously because of a longer observational time in the combined-therapy group, different follow-up investigators, and the potential biases in the retrospective studies, in particular selection bias.

\section{Conclusion}

High-risk resected colon cancer includes stage $\mathrm{B}_{2}-\mathrm{C}_{3}$ has demonstrated more chance for local recurrence compared to the lower stages. The role of adjuvant radiotherapy to improve surgical results in colon cancer is controversial. The present report found no improvement in disease-free survival with postoperative external irradiation. Moreover, treatment-related morbidity and mortality seemed to be higher in the radiotherapy arm.

\section{References}

1. Parker S, Bolden S,Wingo P. Cancer Statistics, 1996. CA 1996; 46:5-27.

2. Skibber JM, Minsky BD, Hoff PM. Cancer of colon. In: DeVita VT, Hellman A, Rosenberg SA, editors. Cancer: Principles and Practice of Oncology". $6^{\text {th }}$ edn. Philadelphia: Lippincott 2001. P. 121671.

3. American Cancer Society: Cancer Facts and Figures-1997. Atlanta, American Cancer Society 1997.

4. Bauer TW, Spitz FR. Adjuvant and neoadjuvant chemoradiation therapy for primary colorectal cancer. Surg Oncol 1998;7:17581.

5. Willett CG, Tepper JE, Cohen AM, Orlow E, Welch CE. Failure patterns following curative resection of colonic carcinoma. Ann Surg 1984;200:685.

6. Minsky BD, Mies C, Rich TA, Recht A, Chaffey JT. Potentially curative surgery of colon cancer: Pattern of failure and survival. J Clin Oncol 1988;6:106-18.

7. Russell AH, Pelton J, Reheis CE, Wisbeck WM, Tong DY, Dawson LE. Adenocarcinoma of the colon: An autopsy study with implications for new therapeutic strategies. CA 1985;56:1446.

8. Rich T, Gunderson LL, Lew R, Galdibini JJ, Cohen AM, Donaldson G. Patterns of recurrence of rectal cancer after potentially curative surgery. CA 1983;52:1317.

9. Moertel CG, Fleming TR, Macdonald JS, Haller DG, Laurie JA, Goodman PJ, et al. Levamisole and fluorouracil for adjuvant therapy of resected colon carcinoma. N EngI J Med 1990;322:3528.

10. Francini G, Petrioli R, Lorenzini L, Mancini S, Armenio S, Tanzini $\mathrm{G}$, et al. Folinic acid and 5-fluorouracil as adjuvant chemotherapy in colon cancer. Gastroenterology 1994;106:899.

11. IMPACT. Efficacy of Analysis of Colon Cancer Trials (IMPACT) investigators. Lancet 1995;345:939.

12. Medical Research Council Rectal Cancer Working Party. Randomized trial of surgery alone versus surgery followed by postoperative radiotherapy for mobile cancer of rectum. Lancet 1996;348: 1610.

13. Willett CG, Tepper JE, Kaufman DS, Shellito PC, Eliseo R, Convery $\mathrm{K}$, et al. Adjuvant postoperative radiation therapy of rectal adenocarcinoma. Am J Clin Oncol 1992;15:371.

14. Tepper JE, Cohen AM, Wood WC, Orlow EL, Hedberg SE. Postoperative radiation therapy of rectal cancer. Int J Radiat Oncol Biol Phys 1987; 13:5.

15. Kopleson G. Adjuvant postoperative radiation therapy for colorectal carcinoma above the peritoneal reflection: I. Sigmoid colon. CA 1983;51:1593-8.

16. Kopleson G. Adjuvant postoperative radiation therapy for colorectal carcinoma above the peritoneal reflection: II. 
Antimesenteric wall ascending and descending colon and cecum. CA 1983;52:633-6.

17. Sheild SE, Gunderson LL, Haddock MG, Wong WW, Nelson H. The treatment of locally advanced colon cancer. Int J Radiat Oncol Biol Phys 1997;37:51-8.

18. Willett CG, Fung CY, Kaufman DS, Efird J, Shellito PC. Postoperative radiation therapy for high risk colon cancer. J Clin Oncol 1993; 11:1112.
19. Estes NC, Giri S, Fabian C. Pattern of recurrence for advanced colon cancer modified by whole abdominal radiation and chemotherapy. Am J Surg 1996;62:546-50.

20. Martenson JA Jr, Willett CG, Sargent DJ, Mailliard JA, Donohue JH, Gunderson LL, et al. Phase III study of adjuvant chemotherapy and radiation therapy compared with chemotherapy alone in the surgical adjuvant treatment of colon cancer: results of intergroup protocol 0130. J Clin Oncol 2004 15;22:3277-83. 